Article

\title{
Ethylene Polymerization and Copolymerization with Polar Monomers Using Nickel Complexes Bearing Anilinobenzoic Acid Methyl Ester Ligand
}

\author{
Hailong Cheng ${ }^{1}$, Yue Su ${ }^{1}$, Yanming $\mathrm{Hu}^{2}$, Xuequan Zhang ${ }^{2}$ and Zhengguo Cai ${ }^{1, *}$ (ib \\ 1 State Key Laboratory for Modification of Chemical Fibers and Polymer Materials, College of Material \\ Science and Engineering, Donghua University, Shanghai 201620, China; chl_111@126.com (H.C.); \\ 18817320298@163.com (Y.S.) \\ 2 Key Laboratory of Synthetic Rubber, Changchun Institute of Applied Chemistry, Chinese Academy of \\ Sciences, Changchun 130022, China; yanminghu@ciac.ac.cn (Y.H.); xqzhang@ciac.ac.cn (X.Z.) \\ * Correspondence: caizg@dhu.edu.cn; Tel.: +86-21-6779-2453
}

Received: 31 May 2018; Accepted: 2 July 2018; Published: 9 July 2018

\begin{abstract}
Neutral nickel complexes containing an anilinobenzoic acid methyl ester ligand are prepared and applied for the ethylene polymerization and copolymerization with polar monomers. The complex C2 containing isopropyl substituent on the aniline ligand conducts ethylene polymerization with high activity and good thermal stability. Most importantly, the catalyst promotes the copolymerization of ethylene and polar monomers with high activity (up to $277 \mathrm{~kg} \cdot \mathrm{mol}^{-1} \cdot \mathrm{h}^{-1}$ ), affording ester-functionalized semicrystalline polyethylene with reasonable polar monomer content (up to $3.20 \mathrm{~mol} \%$ ).
\end{abstract}

Keywords: nickel catalyst; anilinobenzoic acid methyl ester; ethylene; polar monomer; copolymerization

\section{Introduction}

Although polyolefins have been extensively used in a wide range of application, the nonpolarity of polyolefins limits their further application [1]. This limitation could be dramatically improved by the introduction of even a small amount of polar functional groups to the polyolefin backbone [2]. A pioneering discovery was reported by Brookhart and co-workers that the $\alpha$-diimine-nickel/palladium catalysts can initiate direct copolymerization of ethylene with polar monomers in the 1990s [3]. Since then, late-transition-metal catalysts based on palladium complexes have been extensively studied for olefin copolymerization with polar monomers [4-11]. Recently, low cost nickel catalysts were also developed extensively for the synthesis of functionalized polyolefins, although their copolymerization activities and resulting copolymer molecular weight are far from those required for industrial application [12-20].

The significant interest was attracted in developing the neutral nickel catalysts because they exhibit higher tolerance toward functional polar groups [21]. Early examples of SHOP type neutral nickel catalysts have been commercialized for the synthesis of $\alpha$-olefins [22-24]. A series of neutral nickel catalysts bearing salicylaldimine ligands (Chart 1A) was reported by Grubbs et al., which showed excellent tolerance towards polar monomers to give functionalized polyethylene [25-28]. The $\beta$-ketoiminato neutral nickel complexes with six-membered-ring were synthesized and applied as the olefin (co)polymerization catalyst (Chart 1B) [29-37]. Brookhart et al. successively developed the anilinotropone-based (Chart 1C) and anilinoperinaphtenone-based (Chart 1D) neutral nickel catalysts [38-41]. These nickel catalysts exhibited higher activity than 
salicylaldimine neutral nickel catalyst $\mathbf{A}$ in ethylene polymerization. Shiono et al. reported that five-membered anilinonaphthoquinone ligated neutral nickel complexes (Chart 1E) exhibited unique performances for the polymerization of ethylene and norbornene and copolymerization of ethylene with polar monomers [16,42-45]. Recently, we found that a novel six-membered anilinoanthraquinone-based neutral nickel complex promoted random copolymerization of ethylene with norbornene and polar monomers with high activity and good thermal stability (Chart 1F) [46,47]. Here, we report the synthesis, characterization, and application of six-membered neutral nickel complexes bearing anilinobenzoic acid methyl ester ligand for the ethylene polymerization and copolymerization with polar monomers to investigate the electronic effect of the ligand backbone.

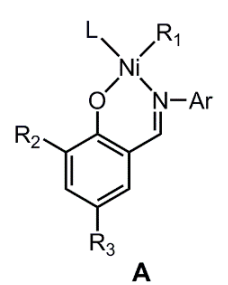

A

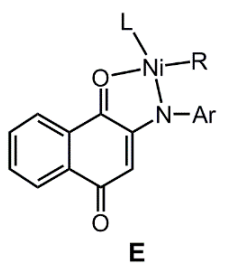<smiles>[R]C1=C([R])N([R])N(CI)OC1[R]</smiles>

B<smiles></smiles><smiles></smiles>

Chart 1. Representative $[\mathrm{N}, \mathrm{O}] \mathrm{Ni}$ Catalysts.

\section{Experimental Section}

\subsection{Materials}

All experiments were performed under dry nitrogen atmosphere using standard Schlenk techniques or in a glovebox. All solvents were dried by the PS-MD-5 (Innovative Technology (China) Ltd., Hong Kong, China) solvent purification system. Ethylene was purified by passage through dehydration column of ZHD-20 and deoxidation column of ZHD-20A before using. Commercial polar monomers were distilled ov'er calcium hydride before using. The other reagents were purchased and used without purification.

\subsection{Analytical Procedure}

NMR spectra were measured on a Bruker Asend ${ }^{\mathrm{TM}} 600$ spectrometer (Bruker, Karlsruhe, Germany). $\mathrm{CDCl}_{3}$ was employed as solvent and the central peak of the solvent was used as an internal reference $\left(\mathrm{CDCl}_{3}, 7.26,\{77.16\} \mathrm{ppm}\right)$. Differential scanning calorimeter (DSC) analyses were carried out on a TA Q2000 instrument (Waters, New Castle, DE, USA). The DSC curves of the samples were recorded under a nitrogen atmosphere at a heating rate of $10^{\circ} \mathrm{C} \cdot \mathrm{min}^{-1}$. The single crystals data was made on a Bruker APEX2 diffractometer (Bruker, Karlsruhe, Germany) using graphite monochromated with Mo K $\alpha$ radiation $(l=0.71073 \AA)$, and the measurement were mounted under nitrogen atmosphere at low temperature. Crystallographic data are summarized in Table S1. Molecular weight and molecular weight distribution of polymers obtained were tested by a polymer laboratory PL GPC-22 (Agilen, Santa Clara, CA, USA) at $150^{\circ} \mathrm{C}$ using 1,2,4-trichlorobenzene as a solvent.

\subsection{General Polymerization Procedure}

Atmospheric pressure polymerization was carried out in a $100 \mathrm{~mL}$ glass reactor equipped with a magnetic stirrer and the high pressure polymerization was performed in Parr Instrument Company autoclave. At first, the reactor was vacuumized at $110{ }^{\circ} \mathrm{C}$ and charged with nitrogen several times 
before polymerization procedure. Then the prescribed amounts of toluene, monomers and cocatalyst under nitrogen were charged into the reactor and polymerization was initiated by adding the catalyst solution at desired temperature and desired pressure. The polymerization was conducted for a certain time and terminated with acidic methanol. The polymer obtained was stirred overnight, collected by filtration, adequately washed with alcohol and acetone, and dried under vacuum at $80{ }^{\circ} \mathrm{C}$ overnight until a constant weight was reached.

\subsection{Synthesis of Ligands and Complexes}

\subsubsection{Synthesis of 2-Anilinobenzoic Acid Methyl Ester Ligand L1}

A solution of bis(dibenzylideneacetone) palladium $\left(\mathrm{Pd}(\mathrm{dba})_{2}\right) \quad(0.230 \mathrm{~g}, 0.4 \mathrm{mmol})$, 1,1'-bis(diphenylphosphino)ferrocene (dppf) $(0.333 \mathrm{~g}, 0.6 \mathrm{mmol})$, Methyl 2-bromobenzoate $(1.42 \mathrm{~mL}$, $10 \mathrm{mmol})$, aniline $(1.1 \mathrm{~mL}, 12 \mathrm{mmol})$ and $\mathrm{CsCO}_{3}(4.89 \mathrm{~g}, 15 \mathrm{mmol})$ in toluene $(100 \mathrm{~mL})$ was heated to $110{ }^{\circ} \mathrm{C}$ and stirred for $24 \mathrm{~h}$ to afford a brown solution. The solvent was evaporated under reduced pressure, and then the residue was dissolved in dichloromethane. The organic phase was washed with water $(20 \mathrm{~mL} \times 5)$ and dried over anhydrous sodium sulfate. Then the solvents were filtrated and evaporated under reduced pressure. The residue 1 was extracted with ether and washed three times by $20 \mathrm{~mL}$ hexane to yield brown oil. Yield $2.091 \mathrm{~g}(92 \%) .{ }^{1} \mathrm{H}$ NMR $\left(\mathrm{CDCl}_{3}\right)$ (Figure S1): $\delta=9.47(\mathrm{~s}, 1 \mathrm{H}$, $-\mathrm{NH}), 7.98-7.96(\mathrm{~d}, J=9.3 \mathrm{~Hz}, 1 \mathrm{H}$, aryl-H), 7.36-7.30 (m, 3H, aryl-H), 7.26-7.24 (m, 3H, aryl-H), 7.11-7.08 $\left(\mathrm{t}, J=7.3 \mathrm{~Hz}, 1 \mathrm{H}\right.$, aryl-H), 6.75-6.72 (t, $J=7.4,7.52 \mathrm{~Hz}, 1 \mathrm{H}$, aryl-H), $3.91\left(\mathrm{~s}, 3 \mathrm{H},-\mathrm{OCH}_{3}\right) .{ }^{13} \mathrm{C}$ NMR $\left(\mathrm{CDCl}_{3}\right.$ ) (Figure S2): $\delta 168.90,147.93,140.77,134.10,131.54,129.38,123.54,122.46,117.11,114.00,111.89$, 51.74. Elemental Analysis: $\mathrm{C}_{14} \mathrm{H}_{13} \mathrm{NO}_{2}$ : Calcd. C 73.99, H 5.77, N 6.16; Found: C 73.34, H 5.35, N 6.23. Elemental Analysis: $\mathrm{C}_{14} \mathrm{H}_{13} \mathrm{NO}_{2}$ : Calcd. C 73.99, H 5.77, N 6.16; Found: C 73.34, H 5.35, N 6.23.

\subsubsection{Synthesis of 2-(2,6-Diisopropylaniline)-Methyl Benzoate Ligand L2}

Ligand L2 was synthesized in a similar way to that for ligand L1. L2 was recrystallized in hexane to yield a reddish crystal. Yield $2.62 \mathrm{~g}(84 \%) .{ }^{1} \mathrm{H} \mathrm{NMR}\left(\mathrm{CDCl}_{3}\right)$ (Figure S3): $\delta 9.03(\mathrm{~s}, 1 \mathrm{H},-\mathrm{NH})$, 7.98-7.97 (dd, $J=8.0,1.5 \mathrm{~Hz}, 1 \mathrm{H}$, aryl-H), 7.38-7.30 (t, 1H, aryl-H), 7.28-7.23 (m, 2H, aryl-H), 7.20-7.17 $(\mathrm{m}, 1 \mathrm{H}$, aryl $-H), 6.63-6.60(\mathrm{td}, J=7.6,0.9 \mathrm{~Hz}, 1 \mathrm{H}$, aryl $-H), 6.22-6.21(\mathrm{~d}, J=8.5 \mathrm{~Hz}, 1 \mathrm{H}$, aryl- $H), 3.95$ $\left(\mathrm{s}, 3 \mathrm{H},-\mathrm{OCH}_{3}\right), 3.17-3,10$ (hept, $\left.J=6.8 \mathrm{~Hz}, 2 \mathrm{H},-\mathrm{CH}\right), 1.19-1.12\left(\mathrm{dd}, J=34.4,6.9 \mathrm{~Hz}, 12 \mathrm{H},-\mathrm{CH}_{3}\right) .{ }^{13} \mathrm{C}$ NMR ( $\mathrm{CDCl}_{3}$ ) (Figure S4): 185.61, 183.97, 155.70, 150.10, 135.23, 134.40, 134.33, 134.02, 133.30, 133.13, 127.07, 127.03, 126.84, 121.49, 117.27, 116.53, 114.14, 104.58, 56.08. Elemental Analysis: $\mathrm{C}_{20} \mathrm{H}_{25} \mathrm{NO}_{2}$ : Calcd. C 77.14, H 8.09, N 4.50; Found: C 77.47, H 7.92, N 4.21. ${ }^{13} \mathrm{C}$ NMR (CDCl3) $\delta 169.41,151.51$, $147.80,134.48,134.45,131.49,127.80,124.01,115.39,113.03,109.59,77.37,77.16,76.95,51.72,28.52,24.74$, $23.14,0.13$.

\subsubsection{Synthesis of Nickel Complex C1}

A mixture of the ligand $\mathbf{L 1}(0.227 \mathrm{~g}, 1 \mathrm{mmol})$ and $\mathrm{KH}(0.044 \mathrm{~g}, 1.1 \mathrm{mmol})$ in $50 \mathrm{~mL}$ of THF was stirred for $3 \mathrm{~h}$ to afford potassium salts of L1. The THF solution of potassium salts was slowly dropped into a solution of trans-[Ni( $\left.\left.\mathrm{PPh}_{3}\right)_{2} \mathrm{PhCl}\right](0.696 \mathrm{~g}, 1 \mathrm{mmol})$ in $5 \mathrm{~mL}$ of the same solvent. The mixture was stirred over night at $25^{\circ} \mathrm{C}$. The reaction mixture was filtered off under a nitrogen atmosphere (PTFE, $0.45 \mu \mathrm{m}$ ) and evaporated under vacuum. The solid thus obtained was purified by recrystallization with a mixture of toluene/hexane to afford crimson single crystals. Yield $0.305 \mathrm{~g}$ (49\%). Elemental Analysis: $\mathrm{C}_{38} \mathrm{H}_{32} \mathrm{NNiO}_{2} \mathrm{P}$, Calcd. C 73.10, H 5.17, N 2.24; Found: C 73.48, H 5.20, N 2.34 .

\subsubsection{Synthesis of Nickel Complex C2}

Complex C2 was synthesized in a similar way to that for Complex C1. C2 was purified by recrystallization with a mixture of THF/hexane to afford orange-red single crystals. Yield $0.291 \mathrm{~g}$ (41\%). Elemental Analysis: $\mathrm{C}_{44} \mathrm{H}_{44} \mathrm{NNiO}_{2} \mathrm{P}$, Calcd. C 74.59, H 6.26, N 1.98; Found:C 74.37, H 6.29, N 2.08. 


\section{Results and Discussion}

\subsection{Synthesis and Molecular Structure of Nickel Complexes}

The synthesis procedure of the ligands $\mathbf{L} \mathbf{1}-\mathbf{L} \mathbf{2}$ and the corresponding nickel complexes $\mathbf{C} 1-\mathbf{C} 2$ is shown in Scheme 1. 2-Anilinobenzoic acid methyl ester ligands were easily obtained by the amination of methyl 2-bromobenzoate in the presence $\mathrm{Pd}(\mathrm{dba})_{2} / \mathrm{dppf}$ and $\mathrm{Cs}_{2} \mathrm{CO}_{3}$ [48]. The nickel complexes were prepared from the reaction of corresponding potassium salt of ligand with 1 equiv of trans-[ $\left.\mathrm{Ni}\left(\mathrm{PPh}_{3}\right)_{2} \mathrm{PhCl}\right]$ in good yields according to the literature procedure [49].

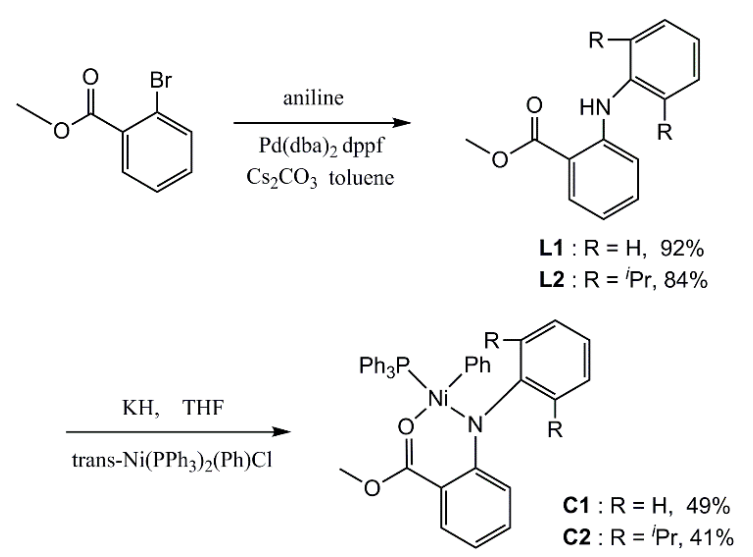

Scheme 1. Synthesis of the Anilinoanthracenequinone Ligands and the Corresponding Nickel Complexes.

The molecular structures of nickel complexes were determined by single-crystal X-ray diffraction analysis (Figure 1). Complexes $\mathbf{C} \mathbf{1}$ and $\mathbf{C} 2$ showed very similar structure in view of the bond distances and the bond angles and exhibited a six-membered $(\mathrm{N}, \mathrm{O})$ nickel chelate ring with a puckered conformation. Each nickel center adopted a square planar coordination geometry, and the phosphine occupied the trans position to the nitrogen.

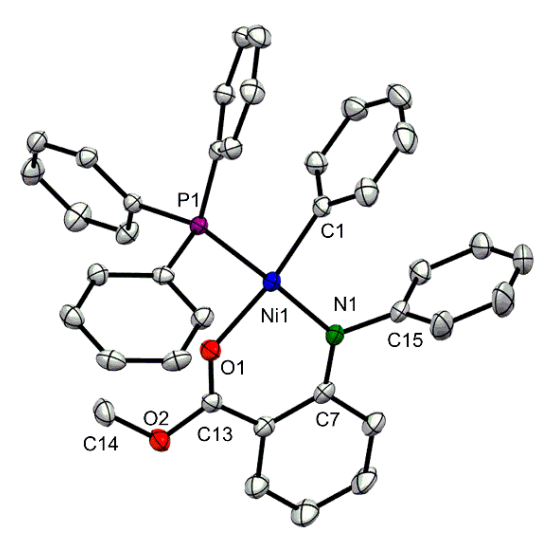

(C1)

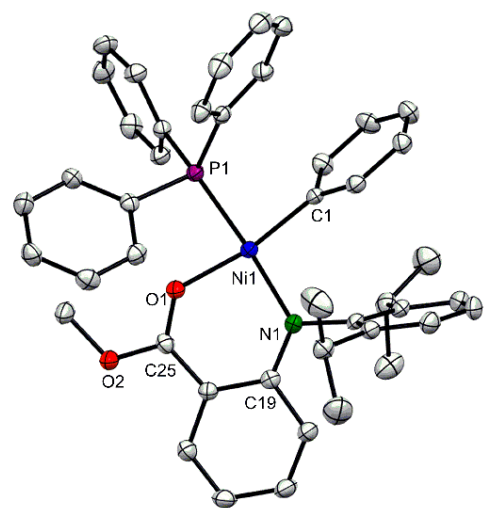

(C2)

Figure 1. Molecular structures of complexes $\mathbf{C} 1$ and $\mathbf{C} 2$. H atoms are omitted for clarity. Selected bond lengths $(\AA)$ and angles (deg) for C1: Ni1-N1 = 1.9223 (14), Ni-C1 = 1.8841 (17), Ni1-O1 = 1.9180 (12), Ni1-P1 = 2.1758 (5), O1-Ni1-N1 = 91.14 (6), C1-Ni1-P1 = 87.12 (5); C2: Ni1-N1 = 1.932 (2), Ni-C1 = 1.891 (2), Ni1-O1 = 1.9193 (17), Ni1-P1 = 2.1816 (7), O1-Ni1-N1 = 91.33 (8), C1-Ni1-P1 = 86.59 (7).

\subsection{Ethylene Polymerization}

The nickel complexes $\mathbf{C} \mathbf{1}$ and $\mathbf{C} \mathbf{2}$ were applied in ethylene polymerization. The results are summarized in Table 1. C1 containing nonsubstituted aniline ligand was inactive regardless of 
the cocatalyst used. In contrast, C2 containing isopropyl substituent on the aniline ligand in the presence of trialkylaluminum-free dried modified methylaluminoxane (dMMAO) or $\mathrm{Ni}(\mathrm{COD})_{2}$ promoted ethylene polymerizaiton with almost the same activities. The results suggested that the substituent on the aniline ligand and the cocatalyst as a phosphine scavenger are necessary for ethylene homopolymerization. The similar effects of the ligand substituent were observed with both cationic and neutral nickel catalyzed ethylene polymerization [3-10]. The $\mathrm{Ni}(\mathrm{COD})_{2}$ system gave high molecular-weight polyethylene (up to $76.3 \mathrm{~kg} \cdot \mathrm{mol}^{-1}$ ) with narrow molecular weight distribution, while the dMMAO system produced ethylene oligomers along with a small amount of polyethylene (entry 2, Table 1). The improved chain transfer rate in the dMMAO system may be attributed to the efficient dissociation of the phosphine, owing to the stronger Lewis acidity of dMMAO than that of $\mathrm{Ni}(\mathrm{COD})_{2}$. The same phenomenon was also reported by Kim et al. by using ketoenamine-based neutral nickel complexes, in which the use of MAO conducted ethylene oligomerization with high activity [50].

Table 1. Ethylene polymerizations with complexes $\mathbf{C} 1$ and $\mathbf{C} 2{ }^{\mathrm{a}}$.

\begin{tabular}{|c|c|c|c|c|c|c|c|c|c|}
\hline Entry & Catalyst & Cocatalyst & P (MPa) & $\operatorname{Temp}\left({ }^{\circ} \mathrm{C}\right)$ & Yield (g) & $\begin{array}{c}\text { Activity } \\
\left(\mathrm{kg} \cdot \mathrm{mol}^{-1} \cdot \mathrm{h}^{-1}\right)\end{array}$ & $M_{\mathrm{n}}{ }^{\mathrm{b}}\left(10^{3}\right)$ & PDI $^{b}$ & $T_{\mathrm{m}}{ }^{\mathrm{c}}\left({ }^{\circ} \mathrm{C}\right)$ \\
\hline 1 & $\mathrm{C} 2$ & - & 1.5 & 40 & 0.06 & 36 & 10.4 & 2.14 & 97.0 \\
\hline $2^{d}$ & $\mathrm{C} 2$ & dMMAO & 1.5 & 40 & oligomer & 616 & - & - & - \\
\hline 3 & $\mathrm{C} 1$ & $\mathrm{Ni}(\mathrm{COD})_{2}$ & 1.5 & 40 & trace & - & - & - & - \\
\hline 4 & $\mathrm{C} 2$ & $\mathrm{Ni}(\mathrm{COD})_{2}$ & 1.5 & 40 & 1.29 & 774 & 12.2 & 2.08 & 90.6 \\
\hline 5 & $\mathrm{C} 2$ & $\mathrm{Ni}(\mathrm{COD})_{2}$ & 1.5 & 20 & 0.14 & 84 & 76.3 & 2.28 & 125.9 \\
\hline 6 & $\mathrm{C} 2$ & $\mathrm{Ni}(\mathrm{COD})_{2}$ & 1.5 & 60 & 0.56 & 336 & 6.9 & 2.11 & 45.2 \\
\hline 7 & $\mathrm{C} 2$ & $\mathrm{Ni}(\mathrm{COD})_{2}$ & 0.5 & 40 & 0.17 & 99 & 8.6 & 1.85 & 87.3 \\
\hline 8 & $\mathrm{C} 2$ & $\mathrm{Ni}(\mathrm{COD})_{2}$ & 3.0 & 40 & 1.46 & 876 & 19.1 & 2.54 & 95.2 \\
\hline
\end{tabular}

${ }^{\text {a }}$ Polymerization conditions: solvent $=$ toluene, total volume $=25 \mathrm{~mL}, \mathrm{Ni}=10 \mu \mathrm{mol}$, time $=10 \mathrm{~min}$, temperature $=40^{\circ} \mathrm{C}$, $\mathrm{Ni}(\mathrm{COD})_{2}=24 \mu \mathrm{mol}, \mathrm{dMMAO}=10 \mathrm{mmol}$. ${ }^{\mathrm{b}}$ Determined by GPC using polystyrene standard. ${ }^{\mathrm{c}}$ Determined by DSC. ${ }^{\mathrm{d}}$ Activity was determined by ${ }^{1} \mathrm{H}$ NMR.

Polymerization activity is strongly depended on the polymerization temperature and the ethylene pressure. The decrease of the temperature to $20^{\circ} \mathrm{C}$ resulted in the decrease of the activity in one order of magnitude (entry 5). Although activity decreased as the temperature was increased to $60^{\circ} \mathrm{C}$ (entry 6), the catalyst still showed high activity of $336 \mathrm{~kg} \cdot \mathrm{mol}^{-1} \cdot \mathrm{h}^{-1}$, indicating good thermal stability of this catalytic system. The reason for the small decrease of the activity at $60{ }^{\circ} \mathrm{C}$ could be attribute to the reduced ethylene concentration at the high polymerization temperature [51]. The molecular weight increased with decreasing the polymerization temperature, indicating that the increase of chain transfer rate is more effective than chain growth rate with rising the polymerization temperature (Figure 2). Further increase in activity and molecular weight was observed by the increase of ethylene pressure at $40^{\circ} \mathrm{C}$. 


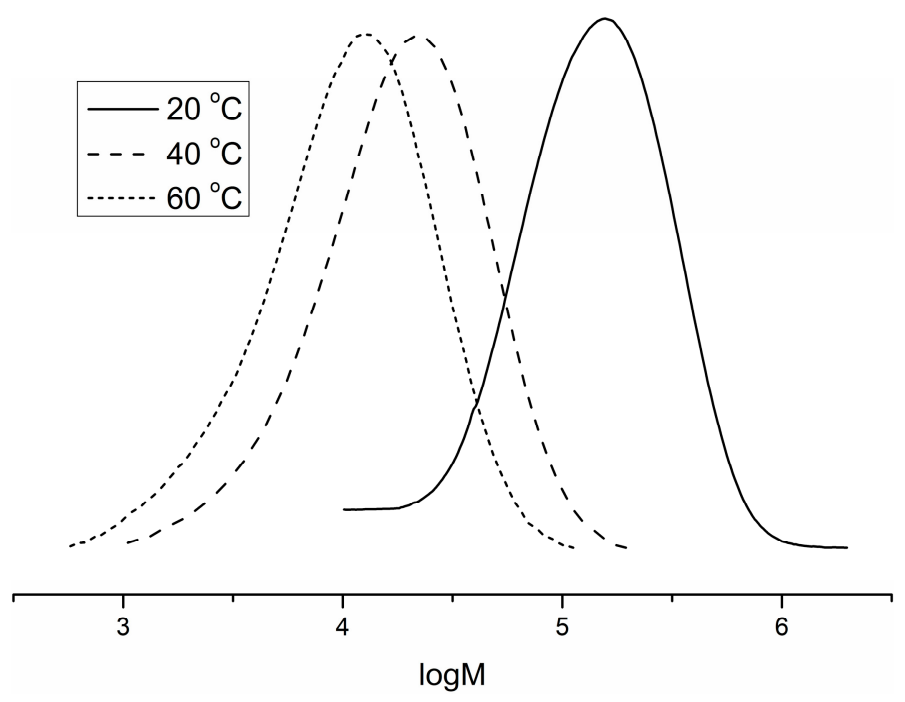

Figure 2. GPC curves of polymers under different polymerization temperatures.

\subsection{Copolymerization of Ethylene with Polar Monomers}

The ethylene copolymerizations with polar monomers such as 5-hexene-1-yl-acetate (HAc), 5-norbornene-2-yl acetate $\left(\mathrm{NB}_{\mathrm{Ac}}\right)$, vinyl acetate (VAc), and methyl acrylate (MA) were conducted (Table 2). Although the $\mathrm{Ni}(\mathrm{COD})_{2}$ system showed slightly higher comonomer incorporation than the dMMAO system, the copolymerization activity of $\mathrm{Ni}(\mathrm{COD})_{2}$ system was much lower than that of the dMMAO system, affording lower molecular weight copolymers (entries 1 and 3). In general, the polymerization of the sterically bulky monomers such as higher $\alpha$-olefins and norbornene catalyzed by the neutral nickel complexes require MAO or MMAO as the phosphine scavenger to provide reasonable monomer coordination site [10].

Table 2. Copolymerization of ethylene with polar monomers using complex $\mathbf{C} 2{ }^{\mathrm{a}}$.

\begin{tabular}{|c|c|c|c|c|c|c|c|c|}
\hline Entry & $\begin{array}{l}\text { Comonomer } \\
(\mathrm{mmol})\end{array}$ & Cocatalyst & Yield (g) & $\begin{array}{c}\text { Activity } \\
\left(\mathrm{kg} \cdot \mathrm{mol}^{-1} \cdot \mathrm{h}^{-1}\right)\end{array}$ & $M_{\mathrm{n}}^{\mathrm{b}}\left(10^{4}\right)$ & PDI $^{b}$ & $\begin{array}{l}T_{\mathrm{m}}{ }^{\mathrm{c}} \\
\left({ }^{\circ} \mathrm{C}\right)\end{array}$ & $\begin{array}{l}\text { Incorp. }^{\mathrm{d}} \\
\text { (mol \%) }\end{array}$ \\
\hline 1 & HAc(30) & $\mathrm{Ni}(\mathrm{COD})_{2}$ & 0.05 & 5 & 0.87 & 1.92 & 97.8 & 1.01 \\
\hline 2 & $\operatorname{HAc}(10)$ & dMMAO & 2.77 & 277 & 1.97 & 2.00 & 97.9 & 0.35 \\
\hline 3 & HAc(30) & dMMAO & 2.01 & 201 & 1.31 & 2.39 & 78.1 & 0.88 \\
\hline 4 & HAc(60) & dMMAO & 1.74 & 174 & 1.17 & 2.16 & 71.4 & 1.33 \\
\hline 5 & $\mathrm{NB}_{\mathrm{Ac}}(30)$ & dMMAO & 1.14 & 114 & 1.52 & 3.21 & 67.1 & 3.20 \\
\hline 6 & $\operatorname{VAc}(30)$ & dMMAO & trace & - & - & - & - & - \\
\hline 7 & MA(30) & dMMAO & trace & - & - & - & - & - \\
\hline
\end{tabular}

a Polymerization conditions: solvent $=$ toluene, total volume $=25 \mathrm{~mL}, \mathrm{Ni}=10 \mu \mathrm{mol}$, pressure $=15 \mathrm{~atm}$, temperature $=40^{\circ} \mathrm{C}$, time $=1 \mathrm{~h}, \mathrm{dMMAO}=10 \mathrm{mmol}, \mathrm{Ni}(\mathrm{COD})_{2}=24 \mu \mathrm{mol} .{ }^{\mathrm{b}}$ Determined by GPC using polystyrene standard.

${ }^{\mathrm{c}}$ determined by DSC. ${ }^{\mathrm{d}}$ Incorporation determined by ${ }^{1} \mathrm{H}$ NMR.

The incorporation of the copolymers obtained was investigated by ${ }^{1} \mathrm{H}$ NMR, and the typical ${ }^{1} \mathrm{H}$ NMR spectra of copolymers obtained by complex $\mathbf{C} 2$ are illustrated in Figure 3 . The signals at $4.06 \mathrm{ppm}$ and $2.05 \mathrm{ppm}$ in copolymers were assigned for $\mathrm{CH}_{2}$ and $\mathrm{CH}_{3}$ protons of ester-group label as a and e, respectively. The microstructure of the E-HAc copolymer was also investigated by ${ }^{13} \mathrm{C}$ NMR to demonstrate the incorporation of polar monomers (Figure S5) [16,52]. HAc incorporation was increased (up to $1.33 \mathrm{~mol} \%$, entry 4 ) by increasing HAc concentration in the feed, although copolymerization activity and copolymer molecular weight were decreased slightly. As compare to the results with complex F [47], anilinobenzoic acid methyl ester-ligated complex $\mathbf{C} 2$ showed slightly lower copolymerization activity and HAc incorporation.

The nickel complex $\mathbf{C} 2$ was also capable of copolymerizing ethylene with 5-norbornene-2-yl acetate $\left(\mathrm{NB}_{\mathrm{Ac}}\right)$ with good activity, generating $\mathrm{E}-\mathrm{NB}_{\mathrm{AC}}$ copolymer with reasonable incorporation 
(3.20 mol \%, in Figure S6)). Unfortunately, the commercial polar comonomers such as VAc, and MA shut down copolymerization activity (entries 6,7). This was mainly caused by the coordination of the carbonyl oxygen atom to the nickel center to generate a stable six-membered nickel chelate compound [4].

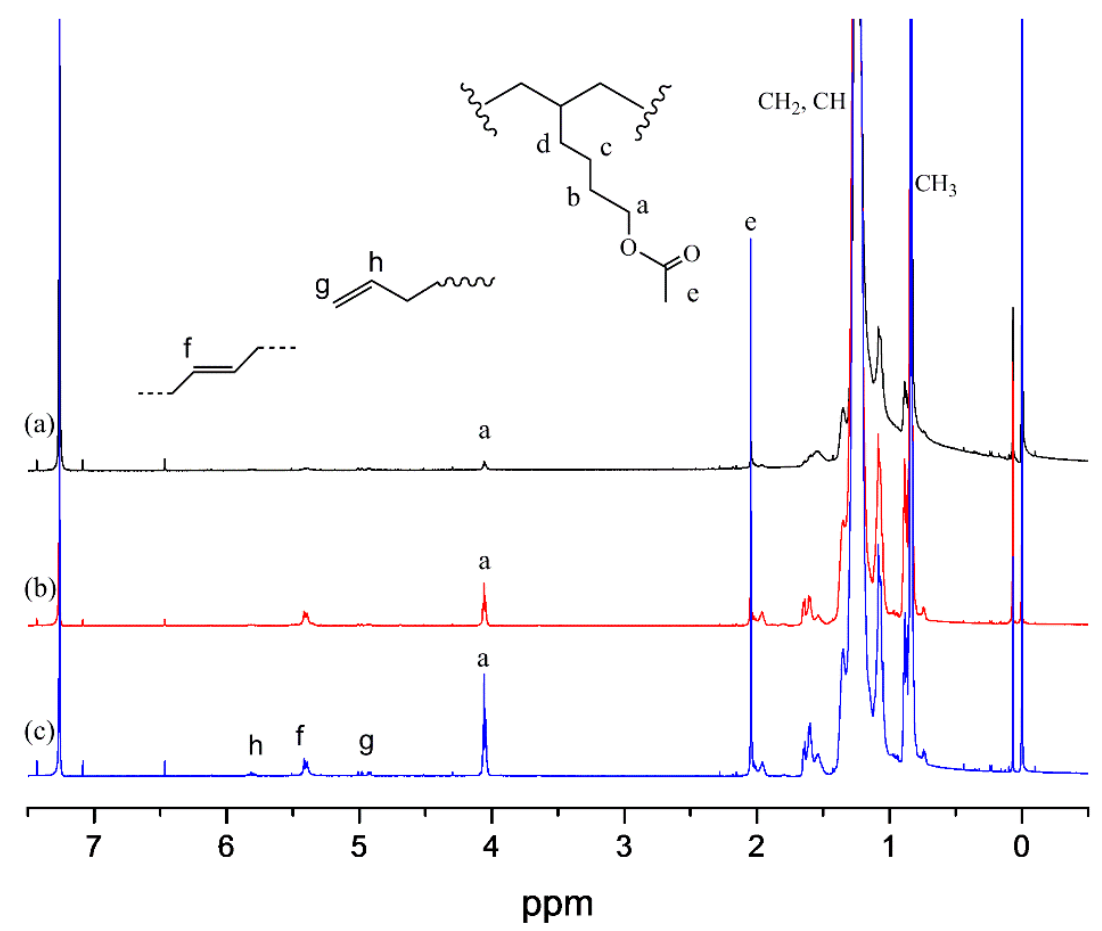

Figure 3. ${ }^{1} \mathrm{H}$ NMR spectra of the E-HAc copolymers: (a) $0.35 \mathrm{~mol} \%$; (b) $0.88 \mathrm{~mol} \%$; (c) $1.33 \mathrm{~mol} \%$.

\section{Conclusions}

In conclusion, neutral nickel complexes bearing anilinobenzoic acid methyl ester ligand have been synthesized and characterized. The steric effect on the aniline ligand played a significant role in the polymerization performances, in which isopropyl substituted complex C2 could enhance ethylene polymerization activity. The complex $\mathbf{C} 2$ was also able to promote copolymerization of ethylene with polar monomers with high activity $\left(114-277 \mathrm{~kg} \cdot \mathrm{mol}^{-1} \cdot \mathrm{h}^{-1}\right)$ and reasonable polar monomer incorporation.

Supplementary Materials: The following are available online at http:/ / www.mdpi.com/2073-4360/10/7/754/s1, Figure S1: ${ }^{1} \mathrm{H}$ NMR spectrum of ligand L1, Figure S2: ${ }^{13} \mathrm{C}$ NMR spectrum of ligand L1. Figure S3: ${ }^{1} \mathrm{H}$ NMR spectrum of ligand L2, Figure S4: ${ }^{13} \mathrm{C}$ NMR spectrum of ligand L2. Figure $\mathrm{S}^{2} \cdot{ }^{13} \mathrm{C}$ NMR spectrum $\left(\mathrm{CDCl}_{3}\right.$, $50{ }^{\circ} \mathrm{C}$ ) of E-HAc copolymer by C2-dMMAO (entry 4, Table 2). Figure S6: ${ }^{1} \mathrm{H}$ NMR spectrum $\left(\mathrm{CDCl}_{3}\right)$ of E-NB-Ac copolymer by C2-dMMAO (entry 5, Table 2). Table S1: Crystal data and structure refinement for complex C1 and complex C2.

Author Contributions: All authors tried their best to contribute effectively to perform and analyze this experimental work. They all participated in the writing of the present manuscript. H.C and Y.S. performed the experimental work and analyzed the data. Y.H. and X.Z. conceived and designed experiments. The settings up of the experimental protocols and the interpretation of the obtained results were performed under the supervision of Z.C.

Funding: This work was funded by National Natural Science Foundation of China (21474013), Program for New Century Excellent Talents in University, the Program for Professor of Special Appointment (Eastern Scholar) at Shanghai Institutions of Higher Learning, "Shu Guang" project supported by Shanghai Municipal Education Commission and Shanghai Education Development Foundation and the Fundamental Research Funds for the Central Universities.

Acknowledgments: The authors thank Tosoh-Finechem Co. for generously donating the MMAO.

Conflicts of Interest: The authors declare no conflict of interest. 


\section{References}

1. Sturzel, M.; Mihan, S.; Mulhaupt, R. From Multisite Polymerization Catalysis to Sustainable Materials and All-Polyolefin Composites. Chem. Rev. 2016, 116, 1398-1433. [CrossRef] [PubMed]

2. Franssen, N.M.G.; Reek, J.N.H.; Bruin, B.D. Synthesis of Functional 'Polyolefins': State of the Art and Remaining Challenges. Chem. Soc. Rev. 2013, 42, 5809-5832. [CrossRef] [PubMed]

3. Ittel, S.D.; Johnson, L.K.; Brookhart, M. Late-Metal Catalysts for Ethylene Homo- and Copolymerization. Chem. Rev. 2000, 100, 1169-1204. [CrossRef] [PubMed]

4. Nakamura, A.; Ito, S.; Nozaki, K. Coordination-insertion copolymerization of fundamental polar monomers. Chem. Rev. 2009, 109, 5215-5244. [CrossRef] [PubMed]

5. Chen, E.Y.X. Coordination Polymerization of Polar Vinyl Monomers by Single-Site Metal Catalysts. Chem. Rev. 2009, 109, 5157-5214. [CrossRef] [PubMed]

6. Camacho, D.H.; Guan, Z. Designing late-transition metal catalysts for olefin insertion polymerization and copolymerization. Chem. Commun. 2010, 46, 7879-7893. [CrossRef] [PubMed]

7. Dong, Z.; Ye, Z. Hyperbranched polyethylenes by chain walking polymerization: Synthesis, properties, functionalization, and applications. Polym. Chem. 2012, 3, 286-301. [CrossRef]

8. Nakamura, A.; Anselment, T.M.J.; Claverie, J.; Goodall, B.; Jordan, R.F.; Mecking, S.; Rieger, B.; Sen, A.; van Leeuwen, P.W.N.M.; Nozaki, K. Ortho-Phosphinobenzenesulfonate: A Superb Ligand for Palladium-Catalyzed Coordination-Insertion Copolymerization of Polar Vinyl Monomers. Acc. Chem. Res. 2013, 46, 1438-1449. [CrossRef] [PubMed]

9. Ye, Z.; Xu, L.; Dong, Z.; Peng, X. Designing polyethylenes of complex chain architectures via Pd-diimine-catalyzed "living" ethylene. Chem. Commun. 2013, 49, 6235-6255. [CrossRef] [PubMed]

10. Mu, H.L.; Pan, L.; Song, D.P.; Li, Y.S. Neutral Nickel Catalysts for Olefin Homo- and Copolymerization: Relationships between Catalyst Structures and Catalytic Properties. Chem. Rev. 2015, 115, 12091-12137. [CrossRef] [PubMed]

11. Carrow, B.P.; Nozaki, K. Transition-Metal-Catalyzed Functional Polyolefin Synthesis: Effecting Control through Chelating Ancillary Ligand Design and Mechanistic Insights. Macromolecules 2014, 47, 2541-2555. [CrossRef]

12. Long, B.K.; Eagan, J.M.; Mulzer, M.; Coates, G.W. SemiCrystalline Polar Polyethylene: Ester-Functionalized Linear Polyolefins Enabled by a Functional-Group-Tolerant, Cationic Nickel Catalyst. Angew. Chem. Int. Ed. 2016, 55, 7106-7110. [CrossRef] [PubMed]

13. Tao, W.; Nakano, R.; Ito, S.; Nozaki, K. Copolymerization of Ethylene and Polar Monomers by Using Ni/IzQO Catalysts. Angew. Chem. Int. Ed. 2016, 55, 2835-2839. [CrossRef] [PubMed]

14. Xin, B.S.; Sato, N.; Tanna, A.; Oishi, Y.; Konishi, Y.; Shimizu, F. Nickel Catalyzed Copolymerization of Ethylene and Alkyl Acrylates. J. Am. Chem. Soc. 2017, 139, 3611-3614. [CrossRef] [PubMed]

15. Chen, M.; Chen, C.L. Design of High-Performance Phosphine Sulfonate Nickel Catalysts for Ethylene Polymerization and Copolymerization with Polar Monomers. ACS Catal. 2017, 7, 1308-1312. [CrossRef]

16. Fu, X.; Zhang, L.J.; Tanaka, R.; Shiono, T.; Cai, Z. Highly Robust Nickel Catalysts Containing Anilinonaphthoquinone Ligand for Copolymerization of Ethylene and Polar Monomers. Macromolecules 2017, 50, 9216-9221. [CrossRef]

17. Li, M.; Wang, X.B.; Luo, Y.; Chen, C.L. A Second-Coordination-Sphere Strategy to Modulate Nickel- and Palladium-Catalyzed Olefin Polymerization and Copolymerization. Angew. Chem. Int. Ed. 2017, 56, 11604-11609. [CrossRef] [PubMed]

18. Zhang, D.; Chen, C.L. Influence of Polyethylene Glycol Unit on Palladium- and NickelCatalyzed Ethylene Polymerization and Copolymerization. Angew. Chem. Int. Ed. 2017, 56, 14672-14676. [CrossRef] [PubMed]

19. Konishi, Y.; Tao, W.J.; Yasuda, H.; Ito, S.; Oishi, Y.; Ohtaki, H.; Tanna, A.; Tayano, T.; Nozaki, K. Nickel-Catalyzed Propylene/Polar Monomer Copolymerization. ACS Macro Lett. 2018, 7, $213-217$. [CrossRef]

20. Chen, M.; Chen, C.L. A Versatile Ligand Platform for Palladium- and Nickel-Catalyzed Ethylene Copolymerization with Polar Monomers. Angew. Chem. Int. Ed. 2018, 57, 3094-3098. [CrossRef] [PubMed]

21. Chen, Z.; Mesgar, M.; White, P.S.; Daugulis, O.; Brookhart, M. Synthesis of Branched Ultrahigh-Molecular-Weight Polyethylene Using Highly Active Neutral, Single-Component Ni(II) Catalysts. ACS Catal. 2015, 5, 631-636. [CrossRef] 
22. Keim, W.; Kowaldt, F.H.; Goddard, R.; Kruger, C. Novel coordination of (benzoylmethylene) triphenylphosphorane in a nickel oligomerization catalyst. Angew. Chem. Int. Ed. 1978, 17, 466-467. [CrossRef]

23. Klabunde, U.; Ittel, S.D. Nickel catalysis for ethylene homo- and co-polymerization. J. Mol. Catal. 1987, 41, 123-134. [CrossRef]

24. Starzewski, K.A.O.; Witte, J. Highly Active Ylide-Nickel Catalysts for the Polymerization of Ethylene. Angew. Chem. Int. Ed. 1985, 24, 599-601. [CrossRef]

25. Wang, C.; Friedrich, S.; Younkin, T.R.; Li, R.T.; Grubbs, R.H.; Bansleben, D.A.; Day, M.W. Neutral Nickel(II)-Based Catalysts for Ethylene Polymerization. Organometallics 1998, 17, 3149-3151. [CrossRef]

26. Younkin, T.R.; Connor, E.F.; Henderson, J.I.; Friedrich, S.K.; Grubbs, R.H.; Bansleben, D.A. Neutral, Single-Component Nickel (II) Polyolefin Catalysts That Tolerate Heteroatoms. Science 2000, 287, 460-462. [CrossRef] [PubMed]

27. Connor, E.F.; Younkin, T.R.; Henderson, J.I.; Waltman, A.W.; Grubbs, R.H. Synthesis of neutral nickel catalysts for ethylene polymerization-the influence of ligand size on catalyst stability. Chem. Commun. 2003, 18, 2272-2273. [CrossRef]

28. Waltman, A.W.; Younkin, T.R.; Grubbs, R.H. Insights into the deactivation of neutral nickel ethylene polymerization catalysts in the presence of functionalized olefins. Organometallics 2004, 23, 5121-5123. [CrossRef]

29. Zhang, D.; Jin, G.X.; Weng, L.H.; Wang, F. Synthesis, Molecular Structures, and Norbornene Addition Polymerization Activity of the Neutral Nickel Catalysts Supported by $\beta$-Diketiminato [N, N], Ketiminato [N, O], and Schiff-Base [N, O] Ligands. Organometallics 2004, 23, 3270-3275. [CrossRef]

30. Chen, Y.F.; Wu, G.; Bazan, G.C. Remote Activation of Nickel Catalysts for Ethylene Oligomerization. Angew. Chem. Int. Ed. 2005, 4, 1108-1112. [CrossRef] [PubMed]

31. Li, X.F.; Li, Y.G.; Li, Y.S.; Chen, Y.X.; Hu, N.H. Copolymerization of Ethylene with Methyl Methacrylate with Neutral Nickel(II) Complexes Bearing $\beta$-Ketoiminato Chelate Ligands. Organometallics 2005, 24, 2502-2510. [CrossRef]

32. Zhang, L.; Brookhart, M.; White, P.S. Synthesis, Characterization, and Ethylene Polymerization Activities of Neutral Nickel(II) Complexes Derived from Anilino-Substituted Enone Ligands Bearing Trifluoromethyl and Trifluoroacetyl Substituents. Organometallics 2006, 25, 1868-1874. [CrossRef]

33. Yu, S.M.; Berkefeld, A.; Gottker-Schnetmann, I.; Muller, G.; Mecking, S. Synthesis of Aqueous Polyethylene Dispersions with Electron-Deficient Neutral Nickel(II) Catalysts with Enolatoimine Ligands. Macromolecules 2007, 40, 421-428. [CrossRef]

34. Song, D.P.; Ye, W.P.; Wang, Y.X.; Liu, J.Y.; Li, Y.S. Highly Active Neutral Nickel(II) Catalysts for Ethylene Polymerization Bearing Modified, $\beta$-Ketoiminato Ligands. Organometallics 2009, 28, 5697-5704. [CrossRef]

35. Song, D.P.; Wu, J.Q.; Ye, W.P.; Mu, H.L.; Li, Y.S. Accessible, Highly Active Single-Component $\beta$-Ketiminato Neutral Nickel(II) Catalysts for Ethylene Polymerization. Organometallics 2010, 29, 2306-2314. [CrossRef]

36. Song, D.P.; Wang, Y.X.; Mu, H.L.; Li, B.X.; Li, Y.S. Observations and Mechanistic Insights on Unusual Stability of Neutra Nickel Complexes with a Sterically Crowded Metal Center. Organometallics 2011, 30, 925-934. [CrossRef]

37. Song, D.P.; Shi, X.C.; Wang, Y.X.; Yang, J.X.; Li, Y.S. Ligand Steric and Electronic Effects on $\beta$-Ketiminato Neutral Nickel(II) Olefin Polymerization Catalysts. Organometallics 2012, 31, 966-975. [CrossRef]

38. Hicks, F.A.; Brookhart, M. A Highly Active Anilinotropone-Based Neutral Nickel(II) Catalyst for Ethylene Polymerization. Organometallics 2001, 20, 3217-3219. [CrossRef]

39. Jenkins, J.C.; Brookhart, M. A Highly Active Anilinoperinaphthenone-Based Neutral Nickel(II) Catalyst for Ethylene Polymerization. Organometallics 2003, 22, 250-256. [CrossRef]

40. Hicks, F.A.; Jenkins, C.J.; Brookhart, M. Synthesis and Ethylene Polymerization Activity of a Series of 2-Anilinotropone-Based Neutral Nickel(II) Catalysts. Organometallics 2003, 22, 3533-3545. [CrossRef]

41. Jenkins, J.C.; Brookhart, M. A Mechanistic Investigation of the Polymerization of Ethylene Catalyzed by Neutral Ni(II) Complexes Derived from Bulky Anilinotropone Ligands. J. Am. Chem. Soc. 2004, 126, 5827-5842. [CrossRef] [PubMed]

42. Okada, M.; Nakayama, Y.; Ikeda, T.; Shiono, T. Synthesis of Uniquely Branched Polyethylene by Anilinonaphthoquinone Ligated Nickel Complex Activated with Tris(pentafluorophenyl)borane. Macromol. Rapid Commun. 2006, 27, 1418-1423. [CrossRef] 
43. Okada, M.; Nakayama, Y.; Shiono, T. Synthesis of anilinonaphthoquinone-based nickel complexes and their application for olefin polymerization. J. Organomet. Chem. 2007, 692, 5183-5189. [CrossRef]

44. Okada, M.; Nakayama, Y.; Shiono, T. Heterogenization of an Anilinonaphthoquinone-Chelated Nickel Complex for Ethylene Polymerization Using Silica-Supported Modified Methylaluminoxane. Mcromol. Chem. Phys. 2014, 215, 1792-1796. [CrossRef]

45. Okada, M.; Nakayama, Y.; Shiono, T. Highly Soluble Polynorbornene Prepared by an Anilinonaphthoquinone-Ligated Nickel Complex via Coordination-Insertion Polymerization. J. Organomet. Chem. 2015, 798, 384-387. [CrossRef]

46. Cheng, H.L.; Cai, Z. (Anilino)anthraquinone Nickel-Catalyzed Random Copolymerization of Norbornene and Ethylene. Chem CatChem 2018, 10, 497-500. [CrossRef]

47. Cai, Z.; Donghua University, Shanghai, China. Unpublished results of our group. 2018.

48. Beletskaya, I.P.; Bessmertnykh, A.G.; Averin, A.D.; Denat, F.; Guilard, R. Palladium-Catalyzed Amination of 1,8- and 1,5-Dichloroanthracenes and 1,8- and 1,5-Dichloroanthraquinones. Eur. J. Org. Chem. 2005, 36, 281-305. [CrossRef]

49. Zeller, A.; Herdtweck, E.; Strassner, T. Structural Characterization and a New One-Pot Synthesis of trans-Chloro(phenyl)bis(triphenylphosphane)nickel(II). Eur. J. Inorg. Chem. 2003, 2003, 1802-1806. [CrossRef]

50. Chandran, D.; Bae, C.; Ahn, I.; Ha, C.S.; Kim, I. Neutral Ni(II) Complexes Based on Keto-Enamine Salicylideneanilines Active for Selective Dimerization of Ethylene. J. Organomet. Chem. 2009, 694, 1254-1258. [CrossRef]

51. Wu, J.L.; Pan, Q.M.; Rempel, G.L. Solubility of Ethylene in Toluene and Toluene/Styrene-Butadiene Rubber Solutions. J. Appl. Polym. Sci. 2005, 96, 645-649. [CrossRef]

52. Terao, H.; Ishii, S.; Mitani, M.; Tanaka, H.; Fujita, T. Ethylene/Polar Monomer Copolymerization Behavior of Bis(phenoxy-imine)Ti Complexes: Formation of Polar Monomer Copolymers. J. Am. Chem. Soc. 2008, 130, 17636-17637. [CrossRef] [PubMed]

(C) 2018 by the authors. Licensee MDPI, Basel, Switzerland. This article is an open access article distributed under the terms and conditions of the Creative Commons Attribution (CC BY) license (http:/ / creativecommons.org/licenses/by/4.0/). 